\title{
Genuine Savings and Sustainability with Resource Diffusion
}

\author{
Rintaro Yamaguchi ${ }^{1}[$
}

Accepted: 4 August 2021 / Published online: 11 August 2021

(C) The Author(s) 2021

\begin{abstract}
We consider a spatial extension of genuine savings and wealth as a capital-based indicator of sustainability. In both inefficient and efficient economies, where well-being is locally or globally maximized, respectively, the well-known Hotelling rule and Hartwick (DixitHammond-Hoel) investment rules and results are extended, depending on the extent of the spatial diffusion of natural capital. It is shown that the net present value of any future change in neighboring resource stocks affects the current change in intergenerational well-being. Numerical examples show the relevance of such parameters as the diffusion rate, discount rate, and marginal utility of consumption. Moreover, they suggest the exact adjustments to be made in aggregating or disaggregating the sustainability of different spatial units, which is not addressed in the current practice of green or wealth accounting.
\end{abstract}

Keywords Genuine savings · Inclusive wealth · Sustainable development - Spatial diffusion

JEL Classification C21 $\cdot \mathrm{C} 22 \cdot \mathrm{Q} 20 \cdot \mathrm{Q} 30 \cdot \mathrm{Q} 56$

\section{Introduction}

Given the current natural capital depletion, is intergenerational well-being improving? This elusive question has been posed in the green accounting literature to study the capitalbased indicator developed. Green accounting aims to measure all the capital assets in the economy that are relevant to intergenerational well-being. If capital assets, weighted by their shadow prices that represent their marginal contribution to well-being, do not decline at a given point in time, then the economy is deemed sustainable at that point. Those relevant capital assets are collectively called inclusive or comprehensive wealth (Arrow et al. 2012; UNU-IHDP and UNEP 2012, 2014); hence, the literature is also referred to as wealth accounting (Lange et al. 2018).

In his seminal paper, Weitzman (1976) stresses that the current-value Hamiltonian, which is typically interpreted as the net national product in utility numeraire, is proportional to intergenerational well-being. This implies that the value of net investment in a comprehensive list of capital assets, which is frequently called genuine savings, is equal

Rintaro Yamaguchi

yamaguchi.rintaro.r41@kyoto-u.jp

1 National Institute for Environmental Studies (NIES), 16-2 Onogawa, Tsukuba 305-8506, Japan 
to the change in intergenerational well-being (Hamilton and Clemens 1999; Dasgupta and Mäler 2000). Relatedly, the Hartwick rule (1977), which suggests investing exhaustible resource rents into reproducible capital, can be rephrased as keeping genuine savings zero. This rule leads to constant consumption (i.e., Hartwick result). The Hartwick rule was subsequently generalized to the Dixit-Hammond-Hoel (DHH) rule of keeping the present value of investments constant (Dixit et al. 1980).

A key challenge in green accounting lies in properly accounting for externalities, which make the change in wealth deviate from the change in well-being. ${ }^{1}$ Examples include carbon emissions and damage as well as transboundary air pollution. Although they do not appear in current capital assets, they affect well-being nonetheless.

To demonstrate this point, it may help to start with a simple example of an underground water aquifer. Imagine that two identical farmers own fractionalized agricultural plots, each tied to their non-replenishable water aquifer. The water aquifers are separate from each other, but the underground borders are physically ill-defined and thus subject to diffusion or seepage. In other words, the property rights to the water aquifer are not perfectly secured. Each farmer extracts groundwater to produce agricultural crops, using the produced capital he/she has aboveground. There is no trade in factor inputs or outputs. Suppose also that each farmer is interested in maximizing his/her own intertemporal well-being.

Now, in the absence of spatial diffusion, what does the index of each individual farmer's intertemporal well-being look like? The green accounting literature tells us that the value of the investment in produced capital net of the value of the extracted water is the correct measure of well-being improvement. This is often called genuine savings, or adjusted net savings, or the change in inclusive (or comprehensive) wealth. Thus, investing the value of the depleted water underground in the accumulation of produced capital aboveground would render each farmer's intertemporal well-being constant. In addition, by both keeping the water underground and extracting the water, the celebrated Hotelling rule emerges in efficient economies, where the marginal product of additional water rises at the rate of return on marginal investment into produced capital.

Acknowledging that the groundwater seeps into the neighboring pool, however, each farmer hastens to extract the water because otherwise part of the water he/she owns diffuses to his/her neighbor's aquifer; hence, his/her neighbor will extract more in the future. This ratchets up the rate of increase in the marginal value of water. Moreover, in the presence of this diffusion, the farmer's intertemporal well-being improvement should appear different. Specifically, in the measurement of the change in natural capital, we now have two added terms, aside from his/her own extraction. The first term is the current increase or decrease in his/her own aquifer due to the diffusion from his/her neighbor's pool. The second term reflects the present value of future changes in his/her neighbor's pool. The latter term is required, as his/her current extraction partially depends on the blessing his/ her neighbor's pool provides. Furthermore, if we relax the assumption that the two farmers are identical, we need to attach different weights to well-being improvement because of the gap in their marginal utility of consumption.

The green accounting literature has developed with nations as spatial units. This is plausible given the nature of the extension of national accounting that attempts to proxy for the economic activities and well-being of those who reside within national borders.

\footnotetext{
1 Another challenge is correctly measuring the shadow prices of capital assets, which typically differ from observable market prices and embody institutional characteristics (Arrow et al. 2003; Fenichel and Abbott 2014).
} 
This macroeconomic aspect, however, has made green accounting insensitive to spatial externalities and heterogeneity, aside from a few exceptions in practice such as carbon emissions and local air pollution. As noted by Dasgupta (2001), "despite the self-evident importance of the spatial aspect of Nature, the welfare economic theory of environmental natural resources is not yet spatially sensitive." Thus, we develop an accounting framework that incorporates the spatial diffusion of natural capital between different spatial units. Our framework therefore offers three contributions, corresponding to Sects. 2, 4, and 5 in the remainder of this paper. ${ }^{2}$

First, the framework enables us to modify the well-known Hotelling rule and generalized Hartwick (Dixit-Hammond-Hoel) results in a way that reflects the specific spatial diffusion rate. In particular, in a setting of interconnected subsoil resource pools, we generalize the framework of symmetric diffusion proposed by Arrow et al. (2003) and van der Ploeg (2011) to heterogeneous diffusion. The Hotelling (1931) rule of the marginal resource rent increasing at the rate of interest involves the extent of spatial diffusion. van der Ploeg (2011) shows that the higher the number of resource owners in society, the more aggressive the extraction that takes place. We instead consider general diffusion, which also affects genuine savings in a way that differs between globally inefficient and efficient economies. In addition, Nash equlibrium outcomes are also studied, which prove to be in the middle ground between these efficient and inefficient economies.

Second, our framework constitutes not only a theoretical update but also an empirical guideline for green accounting. In particular, we apply a reduced form of the asymmetric diffusion of the natural resources between two countries. It is shown that, on top of genuine savings, the decrease in gross inflow from the neighboring country's resource stock, capitalized with the discount rate, needs to be included in the change in intergenerational well-being. In globally efficient economies, the relative shadow price of natural resources is also incorporated. We show an empirical order of the magnitude of this adjustment in a hypothetical example of unidirectional resource diffusion between oil-producing nations.

Third, we apply the framework to the aggregation of sustainability indicators across spatial units. In practice, green accounting typically aggregates wealth in monetary units with no weighting that works out the value of world wealth. However, formally, this needs to be weighted by the marginal utility of the consumption of each spatial unit. Moreover, this weighting also affects the forward-looking spatial diffusion term. Overall, the relevant parameters include the diffusion rate, discount rate, and marginal utility of consumption. In globally efficient economies, the elasticity of marginal utility, commonly known as an inequality aversion parameter, is also required to account for the difference in shadow prices. This neglected aspect of green accounting has become increasingly important, as more critical issues involve planetary boundaries rather than individual countries.

\footnotetext{
${ }^{2}$ Our technical analysis is closely related to recent developments in space and time optimization and spatial dynamics in continuous space, especially studies of the diffusion-induced instability of spatial configuration by Brock and Xepapadeas (2008a, b, 2010, 2020) and Xepapadeas (2010), as well as Quah (2002), Brito (2004), Boucekkine et al. (2009), and Desmet and Rossi-Hansberg (2010), among others. Meanwhile, applications of spatiotemporal optimization in environmental and resource economic problems have also increased. Aside from those already mentioned, Camacho and Pérez-Barahona (2015), Desmet and RossiHansberg (2015), and de Frutos and Martín-Herrán (2019) study the spatiotemporal dimensions of land use dynamics, global warming, and transboundary pollution, respectively. Spatiotemporal modeling has also been applied to the infectious diseases of agricultural products (Goodwin and Piggott 2009), invasive species (Atallah et al. 2017), and water and nitrogen management (Knapp and Schwabe 2008), among others. There is also a parallel understanding between time and space discounting (Yamaguchi and Shah 2020).
} 
Before moving on, it is helpful to clarify terminology. The original Hartwick investment rule (Hartwick 1977) is keeping the value of net investments equal to zero, while the Dixit-Hammond-Hoel (DHH) investment rule (Dixit et al. 1980) is keeping the present value of investments constant. If the technology is stationary and the path is short-run efficient (i.e., satisfying the Hotelling rule), then consumption is constant if and only if the DHH investment rule is satisfied (Dixit et al. 1980). If the technology is stationary and the path is efficient (not only short-run efficient) and feasible, then consumption is constant if and only if the Hartwick rule is satisfied (Mitra 2002; Buchholz et al. 2005; Asheim 2013). In this paper, we study the effects of resource diffusion on consumption and intergenerational well-being under discounted utilitarianism. This means that consumption is not constant, so we focus on the Dixit-Hammond-Hoel (DHH) result, not the original Hartwick (1977) result. Hartwick and DHH results are the consequences that can be obtained when Hartwick and DHH rules are complied, respectively (Asheim et al. 2003). In addition, globally inefficient economy maximizes discounted utility only at a point in space, whereas globally efficient economy maximizes discounted utility across space.

It should be noted that our model imposes some assumptions. First, as is the case with the Hartwick and DHH investment rules, we assume perfect competition, no common pool externalities, perfect capital markets, and no other externalities than the spatial externalities we study (cf. Asheim et al. 2003). Since the model does not allow for any trade of goods or any side payments, the interpretation in terms of different countries in the real world requires caution. Second, the DHH result relies on the Hotelling rule, which effectively implies that the expected rate of increase in the resource rent must equal the given rate of interest. The Hotelling rule sometimes differs from practice (Livernois 2009), partly because the depletion of oil wells is governed by geophysical considerations such as Darcy's law (Anderson et al. 2018). Third, population growth is abstracted away in the current analysis, whereas it needs to be absent or quasi-arithmetic rather than exponential for the DHH rule to be valid (Asheim et al. 2007).

The remainder of this paper is structured in the following manner. In Sect. 2, we present a basic spatiotemporal problem in discrete space, with the Hotelling and DHH investment rules, and non-declining well-being in globally inefficient and efficient economies. Section 3 extends the model to study Nash equlibrium outcomes lying between polar cases in Sect. 2. In Sect. 4, we analyze an intuitive two-country setting with the asymmetric diffusion of natural resources. Section 5 discusses our implications for the aggregation and disaggregation of sustainability indicators in practice. Section 6 summarizes and concludes. The "Appendix" shows previous models in the literature as a special case of our model.

\section{Model}

We begin by imagining a fluid non-renewable resource such as oil, natural gas, or groundwater. Following Sanchirico and Wilen (1999), Smith et al. (2009), Arrow et al. (2003) and van der Ploeg (2011), the resource is fractionalized into $N$ pools numbered by $i=1, \ldots, N$. Resource pools are also tied with their owner-cum-user. The specific resource pool $S_{i}$ is characterized by the following dynamics:

$$
\dot{S}_{i}=-R_{i}+\sum_{j \in 1, \ldots, N} d_{j i} S_{j}=-R_{i}+d_{i i} S_{i}+\sum_{j \neq i} d_{j i} S_{j}
$$


where $R_{i}$ is the human use or extraction from the resource pool $i$. Initial stocks are given by $S_{i}(0)$ for all $i$. The dynamics described in (1) apply well to "point-source" resources such as oil, natural gas, and water aquifers. Other typical natural resources such as gold, bauxite, and cropland do not fall into this category.

The diffusion parameters $d_{j i}$ represent the speed of inflow (diffusivity) of the resource from the pool $j$ to $i$. The self-diffusion of a given pool can be defined as an outflow from $i$ and negative (i.e., $d_{i i}<0$ ). Otherwise, resource inflows from interlinked pools $j$ into $i$ are positive, namely, $d_{j i}>0$ for $j \neq i$. In other words, $d_{i i} S_{i}$ and $\sum_{j \neq i} d_{j i} S_{j}$ represent the gross outflow and gross inflow, respectively. By diffusion, we primarily mean the physical seepage of the resource (cf. Costello and Polasky 2008); however, this is open to socioeconomic interpretations, such as the security of the property rights on the resource (van der Ploeg 2011).

The other class of capital asset is reproducible, which accumulates as output net of consumption:

$$
\dot{K}_{i}=F\left(K_{i}, R_{i}\right)-C_{i},
$$

where $F$ signifies the mapping from capital and resources to output.

Take the time derivative of both sides of the capital dynamics, (2), and obtain

$$
\dot{C}_{i}=F_{K_{i}} \dot{K}_{i}+F_{R_{i}} \dot{R}_{i}-\dot{K}_{i} .
$$

In general, following Dixit et al. (1980), Buchholz et al. (2005) and Asheim (2013), the following fundamental relationship between constant consumption and Hotelling and Hartwick rules (in the absence of diffusion) can be derived:

$$
\dot{C}_{i}=-F_{R_{i}} \frac{d}{d t}\left(\frac{\dot{K}_{i}}{F_{R_{i}}}-R_{i}\right)-\dot{K}_{i}\left(\frac{\dot{F_{R_{i}}}}{F_{R_{i}}}-F_{K_{i}}\right) .
$$

\subsection{Globally Inefficient Economies}

In this subsection, we consider the situation in which owners of resource pools ignore others and rather maximize their own dynamic benefits. First, we define intergenerational well-being.

Definition 1 Let $V_{i}(t)$ denote the intergenerational well-being of $i$ from now to the future:

$$
V_{i}(t)=\int_{t}^{\infty} U\left(C_{i}(\tau)\right) e^{-\delta(\tau-t)} d \tau,
$$

where utility $U$ is a function of consumption $C_{i}$ with declining marginal utility and $\delta>0$ is the pure rate of time preference.

In addition, following the green accounting literature (Arrow et al. 2012), we refer to the state of non-declining intergenerational well-being as sustainable development.

Definition 2 The economic development of $i$ is sustainable at $t$ iff $\partial V_{i}(t) / \partial t \geq 0$. 
We now characterize the economy under individual optimality. The relevant currentvalue Hamiltonian reads

$$
H_{i}=U\left(C_{i}\right)+\lambda_{i}\left(F\left(K_{i}, R_{i}\right)-C_{i}\right)+\mu_{i}\left(-R_{i}+d_{i i} S_{i}+\sum_{j \neq i} d_{j i} S_{j}\right),
$$

where $\lambda_{i}$ and $\mu_{i}$ are the co-state variables associated with capital and resources, respectively. For later purposes, it is useful to define the following.

Definition 3 The genuine savings of $i$, or, equivalently, the change in the inclusive wealth of $i$ in consumption terms, is the weighted sum of the change in capital assets weighted by their shadow prices. For example, in the current inefficient economies, it can be expressed as: $G_{i}:=\dot{K}_{i}+\frac{\mu_{i}}{\lambda_{i}} \dot{S}_{i}$.

Along the optimum, the following usual conditions hold:

$$
\begin{gathered}
U_{C_{i}}=\lambda_{i}, \\
\lambda_{i} F_{R_{i}}=\mu_{i}, \\
-\lambda_{i} F_{K_{i}}=\dot{\lambda}_{i}-\delta \lambda_{i}, \\
-\frac{\partial H_{i}}{\partial S_{i}}=-d_{i i} \mu_{i}=\dot{\mu}_{i}-\delta \mu_{i} .
\end{gathered}
$$

The first and second static efficiency conditions (7) and (8) state that the marginal utility of consumption equates to the marginal product of capital and that the marginal resource rent equates to the scarcity of the resource. The last dynamic efficiency condition (10) only accounts for the gross outflow from the resource pool (i.e., $d_{i i} S_{i}$ ), dismissing any inflows from neighboring sites, which are uncontrollable by the resource owner $i$. This corresponds to the case in which each agent takes the gross inflows from other resources as given.

Combining (8)-(10), we have the following lemma.

Lemma 1 (Hotelling rule in globally inefficient economies) The marginal resource rent increases at a rate equal to the sum of the marginal product of capital and the gross outflow rate of the resource:

$$
\frac{\dot{F_{R_{i}}}}{F_{R_{i}}}=F_{K_{i}}-d_{i i}
$$

Lemma 1 shows that when individual players only care about the fact that their resource flows out to interconnected resource pools, the marginal resource rent increases at a rate faster than the rate of return on capital, as $-d_{i i}>0$. The original Hotelling rule strikes a balance between keeping the resource and earning the capital gain, on the one hand, and extracting the resource to be used in production and earning the marginal product of capital, on the other hand. Lemma 1 complicates the righthand side of the rule by adding the rate of the gross outflow of the resource, because 
resource owners extract resources more now, under the expectation that if they keep the resource under the ground, their neighbors will consume more in the future (van der Ploeg 2011). The rate of increase in the marginal resource rent is larger, other things being equal, as the resource outflow rate $\left(-d_{i i}\right)$ is larger.

Taking the time derivative of the capital dynamics (2) and using Definition 3 (genuine savings) and Lemma 1 (Hotelling rule), we have:

Lemma 2 (Dixit-Hammond-Hoel result in globally inefficient economies) The change in current consumption is the return on genuine savings, net of the change in genuine savings and spatial diffusion. In particular, consumption changes according to

$$
\dot{C}_{i}=F_{K_{i}} G_{i}-\dot{G}_{i}+F_{R_{i}} \sum_{j \neq i} d_{j i} \dot{S}_{j}
$$

Lemma 2 states that the change in current consumption is made up of three components. The first intuitive term is the return on genuine savings, with the rate of return being the marginal product of capital or the real interest rate. When $G_{i}$ is zero, there is no return, such that consumption is constant. The second term is the change in genuine savings. This reflects the fact that, given current income, consumption and savings are a direct tradeoff, meaning that an additional unit of consumption reduces a marginal unit of savings. In other words, if this term is moved to the left-hand side, the sum of the consumption change and savings change is the return on savings, besides the diffusion term. A corollary is that as far as the change rate of savings does not exceed the rate of interest, consumption is non-declining. Both these terms appear in Hamilton and Hartwick (2005). The third additional spatial diffusion term represents the decrease in gross inflows from neighboring resource pools as a result of their current depletion $\left(\dot{S}_{j}<0\right.$ and $d_{j i}>0$ by definition), which places downward pressure on the change in consumption.

Taking the time derivative of intergenerational well-being in Definition 1 and using Lemma 2 (DHH result) as well as the first-order conditions (7) and (9), we obtain

Proposition 1 (Sustainability in globally inefficient economies) The well-being improvement of $i$ is given by

$$
\dot{V}_{i}=\frac{d V_{i}(t)}{d t}=U_{C_{i}} G_{i}+\int_{t}^{\infty} U_{C_{i}} F_{R_{i}} \sum_{j \neq i} d_{j i} \dot{S}_{j} e^{-\delta(\tau-t)} d \tau .
$$

The change in intergenerational well-being is not well represented by genuine savings. In particular, given $d_{j i}<0$ and $\dot{S}_{j}<0$, genuine savings overestimate the change in well-being by the diffusion term. The diffusion term partially holds from Lemma 2, which captures the decrease in gross inflows from interconnected resource pools. In contrast to Lemma 2, the diffusion term is revealed in a forward-looking way, because an indicator of sustainability incorporates all the future diffusion effects with an appropriate discount rate (Aronsson and Löfgren 2010). Proposition 1 is written in the well-being numeraire, and thus the current shadow price of the resource is also added, which is composed of the marginal utility of consumption and marginal product of the resource. By way of a simplified asymmetric diffusion, Sect. 4 discusses this intuition in more detail. 


\subsection{Globally Efficient Economies}

As illustrated, our idea of globally inefficient economies introduced in the previous section is a spatial externality not incorporated into market transactions. In general, it is common practice to assume a social planner to correct externality. However, in our setting, there is no obvious reason the collective world have an incentive to maximize the world's well-being, while being also concerned about the well-being of individual pool. ${ }^{3}$ We thus assume that there exist relative prices for dynamic well-being such that the allocation is efficient even if the dynamic well-being of the different pools could have been exchanged at these prices. In other words, there exist Negishi weights on dynamic well-being such that the weighted sum of dynamic well-being is maximized. Let $\sigma_{i}^{0}$ be the weight assigned to each pool, where $\sum_{i=1}^{N}=1$. Then the total intergenerational well-being across space becomes

$$
\sum_{i=1}^{N} \sigma_{i}^{0}\left(\int_{0}^{\infty} U\left(C_{i}(t)\right) e^{-\delta t} d t\right)
$$

We say that economies are globally efficient if all pool owners use the same vector of weights. To consider such a case, write the present-value Hamiltonian as

$$
H^{p}=\sum_{i=1}^{N} \sigma_{i}^{0} e^{-\delta t} U\left(C_{i}\right)+\sum_{i=1}^{N} \pi_{i}\left[F\left(K_{i}, R_{i}\right)-C_{i}\right]+\sum_{i=1}^{N} \rho_{i}\left(-R_{i}+\sum_{j=1}^{N} d_{j i} S_{j}\right),
$$

where $\pi_{i}$ and $\rho_{i}$ are co-state variables associated with capital and resource at $i$. Define $\sigma_{i}(t):=\sigma_{i}^{0} e^{-\delta t}$ as a discount factor that embodies Negishi weight and the pure rate of time preference. Necessary conditions for optimality include

$$
\begin{gathered}
\sigma_{i} U_{C_{i}}=\pi_{i}, \\
\pi_{i} F_{R_{i}}=\rho_{i}, \\
-\pi_{i} F_{K_{i}}=\dot{\pi}_{i}, \\
-\rho_{i} d_{i i}-\sum_{j \neq i} \rho_{j} d_{i j}=\dot{\rho}_{i} .
\end{gathered}
$$

In (16), the second term appears, in contrast to Eq. (10) in inefficient economies. This results from accounting for the effect of the pool's outflow to other interconnected pools (i.e., from $i$ to $j$ for all $j \neq i)^{4}$. From (13)-(16), the Hotelling rule and DHH result in this setting can be described as follows:

\footnotetext{
${ }^{3}$ The author is grateful to an anonymous referee for this observation and suggesting the weighting approach.

${ }^{4}$ In matrix notation, for the case of $N=3$ for example, (16) forms a system of linear differential equations:

$$
\dot{\rho}=X \rho,
$$
}

where

$$
X=-\left(\begin{array}{lll}
d_{11} & d_{21} & d_{31} \\
d_{12} & d_{22} & d_{32} \\
d_{13} & d_{23} & d_{33}
\end{array}\right)
$$


Lemma 3 (Hotelling rule in globally efficient economies) The resource rent at $i$ increases according to the following:

$$
\frac{\dot{F_{R_{i}}}}{F_{R_{i}}}=F_{K_{i}}-d_{i i}-\sum_{j \neq i} d_{i j} \frac{\sigma_{j}^{0} U_{C_{j}} F_{R_{j}}}{\sigma_{i}^{0} U_{C_{i}} F_{R_{i}}}=F_{K_{i}}-\sum_{j} d_{i j} \frac{\sigma_{j}^{0} U_{C_{j}} F_{R_{j}}}{\sigma_{i}^{0} U_{C_{i}} F_{R_{i}}} .
$$

Lemma 4 (Dixit-Hammond-Hoel result in globally efficient economies) The change in current consumption is the return on genuine savings, net of the change in genuine savings and spatial diffusion. In particular, consumption at $i$ changes according to

$$
\dot{C}_{i}=F_{K_{i}} G_{i}-\dot{G}_{i}+F_{R_{i}}\left(\sum_{j=1}^{N} d_{j i} \dot{S}_{j}-\dot{S}_{i} \sum_{j=1}^{N} d_{i j} \frac{\sigma_{j}^{0} U_{C_{j}} F_{R_{j}}}{\sigma_{i}^{0} U_{C_{i}} F_{R_{i}}}\right) .
$$

Comparing Lemma 1 with Lemma 3, all else equal, the resource price rises more slowly in the efficient economies, since $d_{i j} \geq 0$ for all $j \neq i$ and $\mu_{i} \geq 0$ for all $i$. In Lemma 3, since resource allocation is also optimized across space, we see the internalized effect of a given resource diffusion on neighboring resources, multiplied by relative shadow prices $\left(d_{i j} \rho_{j} / \rho_{i}\right)$. This term also appears in the consumption change in the DHH result, attenuating the effect of an exogenous resource inflow. We arrive at:

Proposition 2 (Sustainability in globally efficient economies) The social well-being improvement of $i$ is given by

$$
\frac{d V_{i}(t)}{d t}=U_{C_{i}} G_{i}+\int_{t}^{\infty}\left(U_{C_{i}} F_{R_{i}} \sum_{j=1}^{N} d_{j i} \dot{S}_{j}-\dot{S}_{i} \sum_{j=1}^{N} d_{i j} \frac{\sigma_{j}^{0}}{\sigma_{i}^{0}} U_{C_{j}} F_{R_{j}}\right) e^{-\delta(\tau-t)} d \tau .
$$

Proof Expressing (3) in present-value utils, we have

$$
\pi_{i} \dot{C}_{i}=\pi_{i} F_{K_{i}} \dot{K}_{i}+\pi_{i} F_{R_{i}} \dot{R}_{i}-\pi_{i} \dot{K}_{i},
$$

which is, using (14) and (15),

$$
\pi_{i} \dot{C}_{i}=-\dot{\pi}_{i} \dot{K}_{i}+\rho_{i} \dot{R}_{i}-\pi_{i} \dot{K}_{i}
$$

so that

$$
\pi_{i} \dot{C}_{i}=-\frac{d}{d t}\left(\pi_{i} \dot{K}_{i}+\rho_{i} \dot{S}_{i}\right)+\dot{\rho}_{i} \dot{S}_{i}+\rho_{i} \dot{S}_{i}+\rho_{i} \dot{R}_{i}
$$

Using (16) and $\dot{S}_{i}=-\dot{R}_{i}+\sum d_{j i} \dot{S}_{j}$, we obtain an extension of Theorem 1 of Dixit et al. (1980):

$$
\pi_{i} \dot{C}_{i}=-\frac{d}{d t}\left(\pi_{i} \dot{K}_{i}+\rho_{i} \dot{S}_{i}\right)+\rho_{i} \sum d_{j i} \dot{S}_{j}-\dot{S}_{i} \sum \rho_{j} d_{i j}
$$

which is another way of stating Lemma 4 . Integrating both sides from $[t, \infty)$ and multiplying both sides by $e^{\delta t} / \sigma_{i}^{0}$, we obtain the expression.

Alternatively, use Lemmas 3 and 4, and the rest of the procedure is the same.

In Proposition 2, added to conventional genuine savings, the net present value of future changes in $i$ 's neighboring pools enter $i$ 's intergenerational well-being in much the same 
way as in Proposition 1. Moreover, the net present value of future changes in $i$ 's own pool is also captured as a result of social optimality.

To guide green national accounting in imperfect economies, Arrow et al. (2003) provide a formulation of interconnected resource pools with mutual physical seepage. van der Ploeg (2011) further studies their resource pools to show that imperfect property rights can lead to rapid resource depletion. ${ }^{5}$ In the "Appendix", we show that our current model is a generalization of their special case in which all resource pools are subject to the same diffusion rate.

Having seen the differences between globally inefficient and efficient economies, a worthy question is how we can fix the former. The usual Pigouvian taxation on the resource extracted would not work well, as we would end up with the same Hotelling rule (i.e., Lemma 1). Moreover, a tax rate proportional to the individual extent of diffusion would be hard to become operational, even if theoretically possible. Thus, policy intervention should aim to correct the diffusion parameters themselves. If the parameters represent the biophysical diffusion of natural resources, then the division of resource pools can be fortressed by reproducible capital such as impermeable panels. If the diffusion parameters are instead more of a proxy of socioeconomic institutions such as the security of property rights and administrative capacity, then monitoring and surveillance systems or capacity building must be beefed up toward governing the quasi commons. ${ }^{6}$

\section{Nash Equilibrium Outcomes}

In Sect. 2, we looked at the polar cases of inefficient and efficient economies. Thus, in this section, we consider open-loop Nash equilibrium (OLNE) outcomes, where each owner is doing the best they can given each other's strategy (Reinganum 1982; Reinganum and Stokey 1985; Kamien and Schwartz 1991). An OLNE is relevant when each player cannot observe each other's play and resource stocks. As the stock size of other players can be induced from one's own behavior and one's own extraction, an OLNE is a strong assumption for our setting. This solution concept is often studied mainly because it is more tractable than a feedback Nash equilibrium and embodies the efficient case as the benchmark. Thus, in an OLNE, decreasing the own extraction does not change the expectation about other players' extraction. However, under resource diffusion, it means that the own stock is higher, leading to more diffusion to other players' stocks (van der Ploeg 2011). We focus on the case of $N=2$ to avoid unnecessary complicaitions.

The resource owner $i$ maximizes (5) subject to (1) for all $j$, as well as to (2). Let $\mu_{i}^{j}$ denote the shadow price of pool $i$ for $j$. One can write the current-value Hamiltonian for $i$ as a function of time, consumption, resource input, capital stock, and resouce stocks of all the owners:

\footnotetext{
5 By contrast, van der Ploeg (2010a) examines a common resource pool to which individual players rush to deplete.

6 Another possible way to close the gap between our inefficient and efficient economies might to convert the former into the latter in keeping with the supply-side environmental policy discussion (e.g., Harstad 2012). That is, the central government may purchase all the resource divisions and issue extracting concessions to the current owners of the resources. Since our $N$ individuals are homogeneous except for the diffusivity of the resources they own, it is socially optimal to issue extracting rights for the same quantity across the board.
} 


$$
H_{i}=u\left(C_{i}\right)+\lambda_{i}\left(F\left(K_{i}, R_{i}\right)-C_{i}\right)+\mu_{i}^{i}\left(-R_{i}+d_{i i} S_{i}+d_{j i} S_{j}\right)+\mu_{j}^{i}\left(-R_{j}+d_{j j} S_{j}+d_{i j} S_{i}\right)
$$

where $i, j=1,2$. The first-order conditions are

$$
\begin{gathered}
U_{C_{i}}=\lambda_{i}, \\
\lambda_{i} F_{R_{i}}=\mu_{i}^{i}, \\
-\lambda_{i} F_{K_{i}}=\dot{\lambda}_{i}-\delta \lambda_{i}, \\
-\frac{\partial H_{i}}{\partial S_{i}}=-d_{i i} \mu_{i}^{i}-d_{i j} \mu_{j}^{i}=\dot{\mu}_{i}^{i}-\delta \mu_{i}^{i}, \\
-\frac{\partial H_{i}}{\partial S_{j}}=-d_{j i} \mu_{i}^{i}-d_{j j} \mu_{j}^{i}=\dot{\mu}_{j}^{i}-\delta \mu_{j}^{i}
\end{gathered}
$$

with transversality conditions. In the same manner as in Sect. 3, from (22)-(25), we have

$$
\frac{\dot{F_{R_{i}}}}{F_{R_{i}}}=F_{K_{i}}-d_{i i}-d_{i j} \frac{\mu_{j}^{i}}{\mu_{i}^{i}}
$$

Note that the last term represents the outflow weighted by the relative shadow price of pool $j$ to pool $i$, from i's perspective. But from integrating (26) with regard to time, the shadow price of pool $j$ to $i$ can be expressed in a forward-looking way:

$$
\mu_{j}^{i}(t)=d_{j i} \int_{t}^{\infty} \mu_{i}^{i}(\tau) e^{-\left(\delta-d_{j j}\right)(\tau-t)} d \tau,
$$

which is the net present value of the shadow price of $i$ 's own pool, weighted by the diffusion from the neighbor to $i, d_{j i}$. Thus, we rewrite (27) to obtain

Lemma 5 (Hotelling rule in OLNE) For $N=2$, the resource rent at $i$ increases according to the following:

$$
\frac{\dot{F_{R_{i}}}}{F_{R_{i}}}=F_{K_{i}}-d_{i i}-d_{i j} d_{j i} \int_{t}^{\infty} \frac{U_{C_{i}}(\tau) F_{R_{i}}(\tau)}{U_{C_{i}}(t) F_{R_{i}}(t)} e^{-\left(\delta-d_{j j}\right)(\tau-t)} d \tau
$$

From (3), Definition 3, and Lemma 4, it is straightforward to show:

Lemma 6 (Dixit-Hammond-Hoel result in OLNE) For $N=2$, the change in current consumption is the return on genuine savings, net of the change in genuine savings and spatial diffusion. In particular, consumption at i changes according to

$$
\dot{C}_{i}=F_{K_{i}} G_{i}-\dot{G}_{i}+F_{R_{i}}\left(d_{j i} \dot{S}_{j}-d_{i j} d_{j i} \dot{S}_{i} \int_{t}^{\infty} \frac{U_{C_{i}}(\tau) F_{R_{i}}(\tau)}{U_{C_{i}}(t) F_{R_{i}}(t)} e^{-\left(\delta-d_{j j}\right)(\tau-t)} d \tau\right) .
$$


It is useful to see incremental changes from the results in Sect. 2. In contrast to Lemmas 1 and 2 for individual efficiency, Lemmas 3-6 all incorporate the outflow to neighboring pools, but Lemmas 3 and 4 for globally efficient economies weight diffusion not by individual but by the global, fully internalized price. Here, Lemmas 5 and 6 also have the terms for diffusion from $i$ to $j$, but they are valued by their worth only to $i$.

Multiplying both sides of Lemma 6 by $U_{C_{i}} e^{-\delta t}$, changing the notation from $t$ to $\tau$, integrating with regard to $\tau$ for $[t, \infty)$, and multiplying both sides again by $e^{\delta t}$, we obtain

Proposition 3 (Sustainability in OLNE) For $N=2$, the social well-being improvement of $i$ is given by

$$
\frac{d V_{i}(t)}{d t}=U_{C_{i}} G_{i}+\int_{t}^{\infty}\left(U_{C_{i}} F_{R_{i}} d_{j i} \dot{S}_{j}-\dot{S}_{i} d_{i j} \mu_{j}^{i}\right) e^{-\delta(\tau-t)} d \tau
$$

where

$$
\mu_{j}^{i}(t)=d_{j i} \int_{t}^{\infty} U_{C_{i}} F_{R_{i}} e^{-\left(\delta-d_{j j}\right)(\tau-t)} d \tau .
$$

Proposition 3 is placed between Propositions 1 and 2, in that externality of the outflow is internalized as in Proposition 2, but only to the extent that it is valued from $i$ 's perspective. If it were $\mu_{j}^{i}=\mu_{j}^{j}$, it would converge to the globally efficient case of Proposition 2, except for the number of owners and Negishi weighting.

\section{Numerical Example}

In this section, we illustrate how the numerical estimations of genuine savings are adjusted for non-renewable resources in the presence of spatial diffusion, using the results provided in Sect. 2.

To prepare for the numerical estimations, we consider a simple asymmetric example of two countries under spatial diffusion. Suppose two otherwise identical neighboring countries, A and B, each endowed with an initial non-renewable natural capital of $S_{A}(0)$ and $S_{B}(0)$, respectively, where $S_{A}(0)<S_{B}(0)$. In addition, we assume asymmetric spatial diffusion, where a constant proportion, $0<\epsilon<1$, of the natural resource of country A diffuses to $\mathrm{B}$ in each period. In this unidirectional setting, the diffusion parameters should read

$$
d_{A A}=-\epsilon, d_{A B}=\epsilon, d_{B B}=0, d_{B A}=0 .
$$

Table 1 summarizes the theoretical results. We start with an inefficient economy in which A and B act independently. For country A, out of which a constant proportion of resource flows, Lemma 1 states that the generalized Hartwick (DHH) rule includes the diffusion rate. The accelerated rate of the resource rent increase revealed in this rule is canceled out by spatial diffusion, meaning that the change in consumption is unaffected, as in Lemma 2. As a result, the change in intergenerational well-being can be proxied for by conventional genuine savings (Proposition 1).

For country B, by contrast, the DHH rule takes the familiar form with no effect of diffusion (Lemma 1), because the resource blessing from its neighbor is outside its control. Spatial diffusion is thus a positive externality, and the consumption change incorporates the decrease in the neighboring pool (Lemma 2). Accordingly, conventional genuine savings 
Table 1 An example of the asymmetric diffusion between the two countries

\begin{tabular}{llll}
\hline Regime & & Country A & Country B \\
\hline Inefficient & & \\
Lemma 1 & $\frac{\dot{F}_{R_{i}}}{F_{R_{i}}}=$ & $F_{K_{A}}+\epsilon$ & $F_{K_{B}}$ \\
Lemma 2 & $\dot{C}_{i}=$ & $F_{K_{A}} G_{A}-\dot{G}_{A}$ & $F_{K_{B}} G_{B}-\dot{G}_{B}+\epsilon F_{R_{B}} \dot{S}_{A}$ \\
Proposition 1 & $\frac{\dot{V}_{i}}{U_{C_{i}}}=$ & $G_{A}$ & $G_{B}+\left(\frac{\epsilon}{\delta}\right) F_{R_{B}} \dot{S}_{A}$ \\
Efficient & $\dot{F}_{R_{i}}=$ & $F_{K_{A}}+\epsilon\left(1-\frac{U_{C_{B}} F_{R_{B}}}{U_{C_{A}} F_{R_{A}}}\right)$ & \\
Lemma 3 & $\dot{F}_{R_{i}}$ & $F_{K_{A}} G_{A}-\dot{G}_{A}-\epsilon \frac{U_{C_{B}}}{U_{C_{A}}} F_{R_{B}} \dot{S}_{A}$ & $F_{K_{B}}$ \\
Lemma 4 & $\dot{C}_{i}=$ & $G_{A}-\left(\frac{\epsilon}{\delta}\right) \frac{U_{C_{B}}}{U_{C_{A}}} F_{R_{B}} \dot{S}_{A}$ & $F_{B} G_{B}-\dot{G}_{B}+\epsilon F_{R_{B}} \dot{S}_{A}$ \\
Proposition 2 & $\frac{\dot{V}_{i}}{U_{C_{i}}}=$ & & $G_{B}+\left(\frac{\epsilon}{\delta}\right) F_{R_{B}} \dot{S}_{A}$ \\
\hline
\end{tabular}

would overstate the change in intergenerational well-being (Proposition 1). The net present value of a future decrease in the neighboring resource pool enters the formula, with a suitable discount rate applied. This represents the value to country B by applying the marginal resource rent for $\mathrm{B}$, not $\mathrm{A}$.

We now turn to a globally efficient economy in which extractions are determined to maximize the intergenerational well-being of $\mathrm{A}$ and $\mathrm{B}$ combined. Because the resource stock of country A affects the resource dynamics and management of both A and B, the resource rent increase also embodies the resource scarcity of both A and B. Consequently, the relative shadow price of $\mathrm{A}$ and $\mathrm{B}$ is internalized in the generalized Hartwick (DHH) rule for A (Lemma 3). Unless the shadow prices of the resource between A and B are equal, the resource rent increases at a rate that deviates from the interest rate. The consumption change of A also internalizes this diffusion effect (Lemma 4). Similarly, the change in the intergenerational well-being of A includes the diffusion effect weighted by the marginal utility of $\mathrm{B}$ relative to $\mathrm{A}$, in addition to the usual genuine savings (Proposition 2). For country $\mathrm{B}$, by contrast, all three theoretical results stay the same as in inefficient economies.

To summarize our results in the fourth and seventh rows (i.e., Propositions 1 and 2) in Table 1, genuine savings $\left(G_{i}\right)$ correctly proxy for the change in intergenerational well-being only for country A, from which the resource constantly diffuses, and only in an inefficient setting. Genuine savings overestimate the sustainability of country B in either regime because they do not reflect the net present value of any future decrease in the resource stock of its neighbor. If the global economy is efficiently managed, the genuine savings of country A should be adjusted upward to reflect the value of the diffusion of its resource to B.

For illustrative purposes, to see the order of magnitude of the adjustment required to reflect the diffusion effect, we hypothesize that subsoil oil diffuses from Kuwait (country A) to Saudi Arabia (country B). ${ }^{7}$ If each country manages its economy independently, the genuine savings of Kuwait can be used with no adjustment. That is, capital investment net

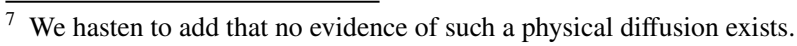


Table 2 A numerical example of the index of the well-being change

\begin{tabular}{lll}
\hline Regime & Country A & Country B \\
\hline $\begin{array}{c}\text { Ineffi- } \\
\text { cient }\end{array}$ & $G_{A}=40.2$ & $G_{B}+\left(\frac{\epsilon}{\delta}\right) F_{R_{B}} \dot{S}_{A}$ \\
& & $=146.3+\left(\frac{0.01}{0.03}\right)(-20.5)=139.5$ \\
Efficient & $G_{A}-\left(\frac{\epsilon}{\delta}\right) \frac{U_{C_{B}}}{U_{C_{A}}} F_{R_{B}} \dot{S}_{A}$ & $($ same as above $)$ \\
& $=40.2-\left(\frac{0.01}{0.03}\right)\left(\frac{13.5}{20.1}\right)^{-2}(-20.5)=55.3$
\end{tabular}

of resource depletion, including resources that diffuse to Saudi Arabia, can correctly show the change in intergenerational well-being. A correct indicator of the well-being change of Saudi Arabia, which partially depends on its neighbor's oil, should be adjusted by the net present value of Kuwait's resource depletion.

Assume, for now, that the diffusion rate is $\epsilon=0.01$ and the social rate of discount is $\delta=0.03$. Average genuine savings in 2012-2016 are 40.2 and 146.3 in Kuwait and Saudi Arabia, respectively, while their energy depletion is 20.5 and 87.9 (in billion USD). ${ }^{8}$ These figures show that both countries have experienced sustainable development in the sense of non-declining wealth in recent years by investing more into other forms of capital than natural capital depletion. Suppose also that the energy rent per unit is the same in both nations (i.e., $F_{R_{A}}=F_{R_{B}}$ ). To account for the adjustment in efficient economies, we need the relative shadow prices of natural capital depletion. A utility function is assumed to have the elasticity of marginal utility of $\eta=2$, so that $U_{C_{i}}=C_{i}^{-2}$. Using the actual average consumption per capita in these countries, we set $C_{A}=20.1$ and $C_{B}=13.5$ in thousand USD.

With these figures in hand, Table 2 summarizes the hypothetical estimates. The current numerical examples show a limited order of magnitude of the diffusion effect for $\mathrm{B}$, adjusted from 146.3 to 139.5 . However, the negative effect of spatial diffusion can overcome the positive genuine savings of $\mathrm{B}$ if the diffusion rate is more than around seven times the discount rate. For country A in an efficient setting, genuine savings are always adjusted upward to indicate sustainability. In the example shown in Table 2, the efficient interpretation of the observables suggests a more optimistic view (55.3) than genuine savings indicate (40.2). This adjustment is subject, among others, to the elasticity of marginal utility, $\eta$. This parameter has multiple interpretations such as inequality aversion, risk aversion, intertemporal substitution, and goods substitution, but inequality aversion would fit our context. The more inequality averse the global society is, the larger the adjustment will be, as society is more concerned about the impact of diffusion in spatial units with different income levels.

Moreover, if A and B are interchanged, so that the resource is assumed to flow out from B (Saudi Arabia) to A (Kuwait), the sustainability of A can turn negative if the diffusion rate is more than half the discount rate. This interchanged example shows that if you partially depend on the resource flowing in from your neighbor that is a large consumer of the resource, then your own sustainability is naturally at more peril. This interpretation can be extended from pure physical diffusion to any ill-defined property rights attached to the resource.

\footnotetext{
${ }^{8}$ Genuine savings and resource depletion are taken from "adjusted net savings, including particulate emission damage" and "energy depletion" (current USD) in World Bank (2018).
} 
Overall, the numerical examples here highlight the importance of the diffusion rate relative to the discount rate (i.e., $\epsilon / \delta$ ) because of the forward-looking nature of the diffusion effect to sustainability. In efficient economies, the elasticity of marginal utility also affects the estimate because the diffusion effect to the neighboring country is internalized there. Of course, the resource rent and marginal utility stay relevant, as in previous green accounting studies, because they constitute the shadow price of natural capital.

\section{Aggregation and Disaggregation Across Spatial Units}

In practical wealth accounting, either the aggregation or the disaggregation of the change in wealth among different spatial units is sometimes performed. For instance, UNU-IHDP and UNEP (2014) reports "world wealth" or "regional wealth" such as Asia and Europe by seemingly simply summing the wealth of the individual nations in US dollars. The report shows that world wealth is composed of produced capital (18\%), human capital (54\%), and natural capital (28\%). By the same token, in their recent update of wealth accounting by the World Bank, Lange et al. (2018) estimate per capita wealth for 2014 as 168,580 US dollars by simply dividing the simple sum of the wealth of all the countries in the world by the global population. However, whether such treatment would bring us to the real change in world social well-being is unclear. Indeed, it is a legitimate treatment only in a globally optimum world. This is not only of theoretical interest but also practically critical, with increased attention being paid to the "planetary boundaries" that calculates global consequences of natural capital consumption. ${ }^{9}$

It is straightforward to examine this point in the asymmetric two-country model shown in the previous section. Using the results in the fourth and seventh rows of Table 1, the change in global well-being in an ineffcient setting reads

$$
\dot{V}_{A}+\dot{V}_{B}=U_{C_{A}}\left[G_{A}+\frac{U_{C_{B}}}{U_{C_{A}}}\left(G_{B}+\left(\frac{\epsilon}{\delta}\right) F_{R_{B}} \dot{S}_{A}\right)\right]
$$

in utils. Set against this is the change in global well-being in a globally efficient world, which is now

$$
\dot{V}_{A}+\dot{V}_{B}=U_{C_{A}}\left[G_{A}+\frac{U_{C_{B}}}{U_{C_{A}}} G_{B}\right] .
$$

This pair of equations delivers the following three points. First, both (34) and (35) show that in the aggregation of the well-being change, genuine savings in consumption need to be weighted by the marginal utility of consumption of the spatial unit under study. Second, in an inefficient economy, the forward-looking term of future spatial diffusion remains in the change in global well-being, as in Eq. (34). Third, in a globally efficient economy, the forward-looking terms that appear in the change in the well-being of A and B cancel each other out, as in Eq. (35); therefore, the correct index can only be computed by using

\footnotetext{
9 In the presence of spatial heterogeneity, Addicott and Fenichel (2019) demonstrate that shadow price functions hinge on the order of spatial aggregation and valuation even within a specific natural capital.
} 
Table 3 A numerical example of the index of the well-being change, globally aggregated

\begin{tabular}{ll}
\hline Regime & \\
\hline Inefficient & $G_{A}+\frac{U_{C_{B}}}{U_{C_{A}}}\left(G_{B}+\left(\frac{\epsilon}{\delta}\right) F_{R_{B}} \dot{S}_{A}\right)=40.2+\left(\frac{13.5}{20.1}\right)^{-2} * 139.5$ \\
Efficient & $G_{A}+\frac{U_{C_{B}}}{U_{C_{A}}} G_{B}=40.2+\left(\frac{13.5}{20.1}\right)^{-2} * 146.3$
\end{tabular}

the weighted sum of genuine savings, as resources are allocated in a way that maximizes global intergenerational well-being.

In summary, given that the inefficient setting is closer to our economy, Eq. (34) shows that the global indicator of sustainability should include the effect of the spatial diffusion between spatial units. Moreover, not only the diffusion effect but also conventional genuine savings should be weighted by the relative marginal utility of consumption. Table 3 shows the aggregation using the numerical example from Sect. 3 .

To rewrite this point in a general format that pertains to Sect. 2, we employ Propositions 1 and 2 to derive global sustainability. First, summing the individual well-being improvement shown in Proposition 1, we obtain

$$
\sum_{i} \dot{V}_{i}=\sum_{i} U_{C_{i}} G_{i}+\int_{t}^{\infty} \sum_{i} U_{C_{i}} F_{R_{i}} \sum_{j \neq i} d_{j i} \dot{S}_{j} e^{-\delta(\tau-t)} d \tau .
$$

This equation, which generalizes (34), implies that in inefficient economies, one needs to adjust for the forward-looking term that represents the weighted sum of the diffusion effect of the resource depletion of neighbors.

By contrast, in a globally efficient state, the summation of the individual well-being improvement disappears from the forward-looking diffusion term. It is immediate from Proposition 2 that the global well-being improvement ends up with

$$
\sum_{i} \dot{V}_{i}=\sum_{i} U_{C_{i}} G_{i}
$$

This shows that if a global government ensures the efficient allocation of resources both dynamically and spatially, simply aggregating genuine savings (i.e., the change in inclusive wealth) is sufficient. Your neighbor's diffusion is already internalized in the sustainability index of yours, so there is no need to adjust for the diffusion once it is included in genuine savings.

Furthermore, even if all the future effects of diffusion are properly accounted for, a different marginal utility of consumption should be attached as weighting factors to the change in wealth, as is apparent in Eqs. (36) and (37). This is not necessarily pronounced in the literature, ${ }^{10}$ largely because wealth accounting has not been concerned with spatial heterogeneity. Considering that the marginal utility of consumption should be largely different among nations, this is another rationale for advising against simply aggregating the increase in "world wealth" as an indicator of world social well-being. It would also raise

\footnotetext{
${ }_{10}$ An explicit account of the different marginal utility of consumption in a cost/benefit analysis can be found in Nyborg (2014). Our discussion differs by focusing on wealth accounting and sustainability assessment.
} 
concerns about aggregating the change in inclusive wealth even within an economy if it is composed of heterogeneous spatial units.

At the other end of the spectrum, the disaggregation of wealth accounting (e.g., from a nation to a state or province) seems to be more challenging. As there is diffusion in natural capital (or any capital asset for that matter), simply disaggregating the capital assets is insufficient to ensure the equivalence between wealth and well-being. As Propositions 1 and 2 suggest, the present value of all the future consequences of resource diffusion should be adjusted. Moreover, the accountant has to know whether the prevailing resource allocation mechanism across space is optimal, as the forward-looking adjustment to inclusive wealth differs from inefficient (Proposition 1) to efficient (Proposition 2) regimes. However, we resort to the inefficient setting (Proposition 1) more often in real-world wealth accounting.

\section{Concluding Remarks}

In this study, we extended genuine savings as an index of capital-based sustainability to incorporate the spatial diffusion of natural capital. Specifically, in a general model of diffusion between resource pools, it was shown that the Hotelling rule and generalized Hartwick (Dixit-Hammond-Hoel) results are adjusted to reflect diffusion onto efficient policies and consumption change. Consequently, we obtained an adjusted indicator of intergenerational well-being, which would be overstated by the genuine savings used in the literature. The additional term is forward looking, as it incorporates the net present value of the effect of decreased diffusion due to the current depletion in a neighboring pool. Proposition 1 contributes to the literature on how to adjust the genuine savings indicator when technology is non-stationary. Normally, we think of this when there is technological progress or in the case of countries having changing terms-of-trade. Here positive external effects lead to the non-stationary technology.

Moreover, forward-looking terms take different forms between inefficient and efficient economies. Proposition 2 is more interesting by analyzing the proper adjustment of the genuine savings indicator in the case where these positive external effects are internalized, leading to additional terms relating to the diffusion of resources from the country in question. The numerical application to the asymmetric diffusion of subsoil resources highlights the relevant parameters that determine the order of magnitude of the adjustment.

We focused on the effect of the spatial interaction of resources. A promising extension would be to allow for the economic interaction of capital. Indeed, resource-rich economies can tap into the international oil market to accumulate economic assets in the form of sovereign wealth funds. This open-economy setting has many implications. For example, the value of the depletion of natural capital may be offset by the accumulation of net foreign assets. Moreover, if the marginal resource rent is expected to increase, genuine savings look negative for the time being (Vincent et al. 1997). van der Ploeg (2010b) also points out many other possible reasons for negative genuine savings, including anticipated technical progress in the extraction technology. Formally, this resembles the forward-looking term in Propositions 1 and 2 in our analysis of the spatial diffusion of resources.

On the empirical front, a straightforward extension of our study is to apply the spatial diffusion to natural resources either between or within nations as well as negative stock externalities. Green accounting has developed as an extension of national accounting, which has paid insufficient attention to spatial heterogeneity. As discussed in Sect. 5, this 
goes for both spatial diffusion and the different marginal utility in subregions. The aggregation of, or disaggregation into, subregions with a suitable account of spatial diffusion would enable us to put regional disparities into sharp relief, which tend to be glossed over in national accounting.

The application to negative stock diffusion is also relevant. Carbon damage, the largest stock externality, is incorporated into green accounting using the social cost of carbon estimates (UNU-IHDP and UNEP 2014; World Bank 2018). This can be performed with relative ease because the carbon stock is a global public bad that does not require regional diffusion dynamics (Arrow et al. 2012). A negative stock diffusion of a more local nature, by contrast, has not been fully addressed. In theory, flow pollutants do not affect green accounting, only stock pollutants do (Pezzey 2004); however, the distinction between the two may be practically challenging. Some studies have added particulate matter under the tacit understanding that it comes from a domestic stock source (World Bank 2018). With sufficient data and stock dynamics, our model could be applicable to transboundary stock pollution by adding the forward-looking term of the expected change in the stock source of pollution as well as adjusted marginal utility.

At a global level, the value of the change in natural capital could be aggregated according to the procedure in Sect. 5, with the different marginal utility attached as weighting factors in a way that differs from the simple summation currently performed. The diffusion of natural capital into a poorer constituency, for example, may be related to a higher shadow price. This aggregation exercise that ultimately gets us to world wealth would thus be a critical piece of information, as it indicates whether we are nearing or have crossed wellknown planetary boundaries.

\section{Appendix: Example-Symmetric Diffusion}

In this "Appendix", we show that the symmetric resource pools analyzed by van der Ploeg (2011) are embedded into our model presented in Sect. 2. To see this, suppose each pool is symmetric with a constant diffusivity of $\epsilon$ instead of $d_{j i}$. Formally, we have $d_{j i}=\epsilon$ for all $j \neq i$ and $d_{i i}=-(N-1) \epsilon$, as there are $N-1$ interconnected pools out of which the resource flows. Lemma 1 suggests that the resource price moves according to

$$
\frac{\dot{F_{R_{i}}}}{F_{R_{i}}}=F_{K_{i}}-d_{i i}=F_{K_{i}}+(N-1) \epsilon
$$

in an inefficient economy. This is the political Hotelling rule (van der Ploeg 2011) where non-cooperative agents rush to withdraw non-renewable resources, thereby accelerating the resource price rise. The more factions there are $(N)$, the more aggressive the resource extraction becomes.

By contrast, Lemma 3 leads to

$$
\frac{\dot{F_{R_{i}}}}{F_{R_{i}}}=F_{K_{i}}-d_{i i}-\sum_{j \neq i} d_{i j} \frac{\mu_{j}}{\mu_{i}}=F_{K_{i}}+\left(N-1-\sum_{j \neq i} \frac{\sigma_{j}^{0}}{\sigma_{i}^{0}} \frac{\mu_{j}}{\mu_{i}}\right) \epsilon
$$

in a globally efficient economy. This is the rule when the global optimum is ensured by a social planner. The above expression clarifies that, in general, simply integrating multiple regions into one does not entail the conventional Hotelling rule. If the shadow prices of 
every pool are equalized across space for one reason or another $\left(\mu_{j}=\mu_{i}\right.$ for all $\left.j \neq i\right)$, then the second term on the right-hand side disappears and the conventional rule $\dot{F}_{R_{i}} / F_{R_{i}}=F_{K_{i}}$ applies.

Consumption dynamics can be described as

$$
\begin{gathered}
\dot{C}_{i}=F_{K_{i}} G_{i}-\dot{G}_{i}+\epsilon F_{R_{i}} \sum_{j \neq i} \dot{S}_{j}, \\
\dot{C}_{i}=F_{K_{i}} G_{i}-\dot{G}_{i}+\epsilon F_{R_{i}}\left(\sum_{j \neq i} \dot{S}_{j}-\dot{S}_{i} \sum_{j \neq i} \frac{\sigma_{j}^{0}}{\sigma_{i}^{0}} \frac{\mu_{j}}{\mu_{i}}\right)
\end{gathered}
$$

in inefficient and efficient regimes, respectively.

Finally, the change in local social well-being in utility units is

$$
\begin{gathered}
\dot{V}_{i}=U_{C_{i}} G_{i}+\epsilon \int_{t}^{\infty} \mu_{i} \sum_{j \neq i} \dot{S}_{j} e^{-\delta(\tau-t)} d \tau, \\
\dot{V}_{i}=U_{C_{i}} G_{i}+\epsilon \int_{t}^{\infty}\left(\mu_{i} \sum_{j \neq i} \dot{S}_{j}-\dot{S}_{i} \sum_{j \neq i} \frac{\sigma_{j}^{0}}{\sigma_{i}^{0}} \mu_{j}\right) e^{-\delta(\tau-t)} d \tau,
\end{gathered}
$$

in inefficient and efficient regimes, respectively.

Acknowledgements I have substantially benefited from journal reviewer comments, as well as suggestions from the Co-Editor Anastasios Xepapadeas. This paper stems from a manuscript entitled "Sustainability and spatial externality in capital-resource economies" containing both discrete and continuous spatial analysis, presented at the 5th WCERE 2014 in Istanbul and SEEPS 2017 in Kochi. For helpful comments, I would like to thank Robert Cairns, Eli Fenichel, Justin Johnson Kakeu, Rui Mota, Shintaro Nakagawa, Yasuhiro Nakamoto, Ayumi Onuma, and Timothy J. Richards. However, all remaining errors are the author's. This research is partially funded by KAKENHI Grant Numbers JP16K16237, JP19K12466, JP23241019, and JP26000001 by the Japan Society for the Promotion of Science.

Open Access This article is licensed under a Creative Commons Attribution 4.0 International License, which permits use, sharing, adaptation, distribution and reproduction in any medium or format, as long as you give appropriate credit to the original author(s) and the source, provide a link to the Creative Commons licence, and indicate if changes were made. The images or other third party material in this article are included in the article's Creative Commons licence, unless indicated otherwise in a credit line to the material. If material is not included in the article's Creative Commons licence and your intended use is not permitted by statutory regulation or exceeds the permitted use, you will need to obtain permission directly from the copyright holder. To view a copy of this licence, visit http://creativecommons.org/licenses/by/4.0/.

\section{References}

Addicott ET, Fenichel EP (2019) Spatial aggregation and the value of natural capital. J Environ Econ Manag 95:118-132

Anderson ST, Kellogg R, Salant SW (2018) Hotelling under pressure. J Political Econ 126(3):984-1026

Aronsson T, Löfgren K-G (eds) (2010) Handbook of environmental accounting. Edward Elgar Publishing, Cheltenham

Arrow KJ, Dasgupta P, Mäler KG (2003) Evaluating projects and assessing sustainable development in imperfect economies. Environ Resour Econ 26(4):647-685 
Arrow KJ, Dasgupta P, Goulder LH, Mumford KJ, Oleson K (2012) Sustainability and the measurement of wealth. Environ Dev Econ 17(03):317-353

Asheim GB (2013) Hartwick's rule. In: Shogren J (ed) Encyclopedia of energy, natural resource and environmental economics, vol 2. Elsevier, Amsterdam, pp 314-320

Asheim GB, Buchholz W, Withagen C (2003) The Hartwick rule: myths and facts. Environ Resour Econ 25(2):129-150

Asheim GB, Buchholz W, Hartwick JM, Mitra T, Withagen C (2007) Constant savings rates and quasi-arithmetic population growth under exhaustible resource constraints. J Environ Econ Manag 53(2):213-229

Atallah SS, Gómez MI, Conrad JM (2017) Specification of spatial-dynamic externalities and implications for strategic behavior in disease control. Land Econ 93(2):209-229

Boucekkine R, Camacho C, Zou B (2009) Bridging the gap between growth theory and the new economic geography: the spatial Ramsey model. Macroecon Dyn 13(1):20-45

Brito P (2004) The dynamics of growth and distribution in a spatially heterogeneous world. DE Working papers no 14-2004/DE/UECE

Brock W, Xepapadeas A (2008a) Diffusion-induced instability and pattern formation in infinite horizon recursive optimal control. J Econ Dyn Control 32(9):2745-2787

Brock W, Xepapadeas A (2008b) General pattern formation in recursive dynamical systems models in economics. Mimeo, New York

Brock W, Xepapadeas A (2010) Pattern formation, spatial externalities and regulation in coupled economicecological systems. J Environ Econ Manag 59(2):149-164

Brock W, Xepapadeas A (2020) Spatial environmental and resource economics. DEOS working papers 2002. Athens University of Economics and Business

Buchholz W, Dasgupta S, Mitra T (2005) Intertemporal equity and Hartwick's rule in an exhaustible resource model. Scand J Econ 107(3):547-561

Camacho C, Pérez-Barahona A (2015) Land use dynamics and the environment. J Econ Dyn Control 52:96-118

Costello C, Polasky S (2008) Optimal harvesting of stochastic spatial resources. J Environ Econ Manag 56(1):1-18

Dasgupta P (2001) Human well-being and the natural environment. Oxford University Press, Oxford

Dasgupta P, Mäler K-G (2000) Net national product, wealth, and social well-being. Environ Dev Econ 5:69-93

de Frutos J, Martín-Herrán G (2019) Spatial effects and strategic behavior in a multiregional transboundary pollution dynamic game. J Environ Econ Manag 97:182-207

Desmet K, Rossi-Hansberg E (2010) On spatial dynamics. J Reg Sci 50(1):43-63

Desmet K, Rossi-Hansberg E (2015) On the spatial economic impact of global warming. J Urban Econ $88: 16-37$

Dixit A, Hammond P, Hoel M (1980) On Hartwick's rule for regular maximin paths of capital accumulation and resource depletion. Rev Econ Stud 47(3):551-556

Fenichel EP, Abbott JK (2014) Natural capital: from metaphor to measurement. J Assoc Environ Resour Econ 1:1-27

Goodwin BK, Piggott NE (2009) Spatiotemporal modeling of Asian citrus canker risks: implications for insurance and indemnification fund models. Am J Agr Econ 91(4):1038-1055

Hamilton K, Clemens M (1999) Genuine savings rates in developing countries. World Bank Econ Rev 13(2):333-356

Hamilton K, Hartwick JM (2005) Investing exhaustible resource rents and the path of consumption. Can J Econ 38(2):615-621

Harstad B (2012) Buy coal! A case for supply-side environmental policy. J Political Econ 120(1):77-115

Hartwick JM (1977) Intergenerational equity and the investing of rents from exhaustible resources. Am Econ Rev 67(5):972-974

Hotelling H (1931) The economics of exhaustible resources. J Political Econ 39(2):137-175

Kamien MI, Schwartz NL (1991) Dynamic optimization: the calculus of variations and optimal control in economics and management, 2nd edn. Elsevier, Amsterdam

Knapp KC, Schwabe KA (2008) Spatial dynamics of water and nitrogen management in irrigated agriculture. Am J Agric Econ 90(2):524-539

Lange G-M, Wodon Q, Carey K (eds) (2018) The changing wealth of nations 2018: building a sustainable future. World Bank, Washington, DC

Livernois J (2009) On the empirical significance of the Hotelling rule. Rev Environ Econ Policy 3(1):22-41

Mitra T (2002) Intertemporal equity and efficient allocation of resources. J Econ Theory 107(2):356-376

Nyborg K (2014) Project evaluation with democratic decision-making: what does cost-benefit analysis really measure? Ecol Econ 106:124-131 
Pezzey JCV (2004) One-sided sustainability tests with amenities, and changes in technology, trade and population. J Environ Econ Manag 48(1):613-631

Quah D (2002) Spatial agglomeration dynamics. Am Econ Rev 92(2):247-252

Reinganum JF (1982) A dynamic game of R and D: patent protection and competitive behavior. Econometrica 50(3):671-688

Reinganum JF, Stokey NL (1985) Oligopoly extraction of a common property natural resource: the importance of the period of commitment in dynamic games. Int Econ Rev 26(1):161-173

Sanchirico JN, Wilen JE (1999) Bioeconomics of spatial exploitation in a patchy environment. J Environ Econ Manag 37(2):129-150

Smith MD, Sanchirico JN, Wilen JE (2009) The economics of spatial-dynamic processes: applications to renewable resources. J Environ Econ Manag 57(1):104-121

UNU-IHDP and UNEP (2012) Inclusive wealth report 2012. Cambridge University Press, New York

UNU-IHDP and UNEP (2014) Inclusive wealth report 2014. Cambridge University Press, New York

van der Ploeg F (2010a) Voracious transformation of a common natural resource into productive capital. Int Econ Rev 51(2):365-381

van der Ploeg F (2010b) Why do many resource-rich countries have negative genuine saving? Anticipation of better times or rapacious rent seeking. Resour Energy Econ 32:28-44

van der Ploeg F (2011) Rapacious resource depletion, excessive investment and insecure property rights: a puzzle. Environ Resour Econ 48(1):105-128

Vincent JR, Panayotou T, Hartwick JM (1997) Resource depletion and sustainability in small open economies. J Environ Econ Manag 33(3):274-286

Weitzman ML (1976) On the welfare significance of national product in a dynamic economy. Q J Econ 90(1):156-162

World Bank (2018) World Development Indicators. www.databank.worldbank.org/source/world-devel opment-indicators. Accessed 13 Apr 2020

Xepapadeas A (2010) The spatial dimension in environmental and resource economics. Environ Dev Econ 15(6):747-758

Yamaguchi R, Shah P (2020) Spatial discounting of ecosystem services. Resour Energy Econ 62. https://doi. org/10.1016/j.reseneeco.2020.101186

Publisher's Note Springer Nature remains neutral with regard to jurisdictional claims in published maps and institutional affiliations. 